\title{
Discussion Paper Developing a Customer-Driven Credit Card: Testing Consumer-Issuer Collaboration in the Barclays Ring Community
}

\section{Tom Akana}

Federal Reserve Bank of Philadelphia

Consumer Finance Institute
DP 19-04

October 2019

https://doi.org/10.21799/frbp.dp.2019.04 


\title{
Developing a Customer-Driven Credit Card: Testing Consumer-Issuer Collaboration in the Barclays Ring Community
}

\author{
Tom Akana* \\ Federal Reserve Bank of Philadelphia
}

October 2019

\begin{abstract}
Summary
The Consumer Finance Institute hosted a workshop in November 2018, featuring Paul Wilmore, then chief marketing officer of Barclays US, to discuss the Barclays Ring credit card program. Through the Ring online community, Barclays engages cardholders directly in the program management, sharing detailed profit and loss data, seeking input on program features, and soliciting ideas on how to better create a relationship between the issuer and the customer. Wilmore reviewed the history of the Ring program and provided an overview of the key successes and challenges Barclays has encountered. This paper summarizes Wilmore's presentation and provides additional research on online communities.
\end{abstract}

Keywords: credit cards, online community, participation inequality, gamification JEL codes: D14, D91, O35

${ }^{*}$ Federal Reserve Bank of Philadelphia, Ten Independence Mall, Philadelphia, PA 19106-1574; email: tom.akana@phil.frb.org.

Disclaimer: This Philadelphia Fed discussion paper represents preliminary research that is being circulated for discussion purposes. The views expressed in these papers are solely those of the authors and do not necessarily reflect the views of the Federal Reserve Bank of Philadelphia or the Federal Reserve System. Nothing in the text should be construed as an endorsement of any organization or its products or services. Any errors or omissions are the responsibility of the authors. No statements here should be treated as legal advice. Philadelphia Fed discussion papers are free to download at https://www.philadelphiafed.org/consumer-finance-institute/publications.

Note: All product and program characteristics relating to the Barclays Ring credit card and Ring Online Community are accurate as of the date of the workshop on November 9, 2018. Pricing, benefits, community structure, and similar characteristics may not reflect changes made by Barclays after that date. 


\section{Introduction}

On November 9, 2018, the Federal Reserve Bank of Philadelphia's Consumer Finance Institute hosted Paul Wilmore, the chief marketing officer of Barclays US at the time, to conduct a workshop on a unique credit card program: the Barclays Ring Community. Wilmore described the origins of the program, how it has evolved since its launch in 2012, and some of Barclays' learnings about customer engagement in an online community and the benefits of information sharing in a credit card program.

At its core, the Ring card is a traditional credit card product; its uniqueness comes from an online community of cardholders that enables a high level of direct interaction between the customer base and the Barclays employees who manage the product. In addition to easy access to employees and other financial management resources, Ring customers can see detailed financial reports on the portfolio, submit ideas for new features or products, and participate by voting to determine everything from new fee structures to new plastic designs. By allowing their customers to understand more about how the product's finances work and to participate in the management of the program over time, Barclays hopes to create a more financially engaged customer base and learn more directly about which aspects of the program are the most meaningful to the consumer.

The idea for Ring began to germinate in 2011 as Barclays was looking for a way to address three emerging trends in the credit card marketplace: 1) regulatory changes began affecting the revenue structure of general purpose card programs after 2010, ${ }^{1} 2$ ) the Internet and social media as sources of consumer information and feedback were changing the consumer/company interaction model, and 3) the trust in banks was declining rapidly after the financial crisis. ${ }^{2}$ Barclays believed that creating a personal connection to the product and the community rather than to the bank would foster a more loyal and active customer base in the new environment.

\footnotetext{
${ }^{1}$ The Credit Card Accountability Responsibility and Disclosure (CARD) Act of 2009 contained legislation relating to fees, repricing actions, and other aspects of general purpose credit programs. Benton (2010) provides an excellent overview of the primary rules implementing the CARD Act. A large volume of work examining the expected and actual impact of the act on the credit card ecosystem has been published. Examples include Bar-Gill and Bubb (2012); Debbaut, Ghent, and Kudlyak (2016); Jambulapati and Stavins (2014); Nelson (2018); Santucci (2015); Agarwal, Chomsisengphet, Mahoney, and Stroebel (2014); and Consumer Financial Protection Bureau (2013, 2015, 2017).

${ }^{2}$ The Chicago Booth/Kellogg School Financial Trust Index shows that, while banks were the most trusted portions of the index immediately after the Great Recession, trust decreased precipitously between December 2010 and December 2011, dropping by nearly one-third, from 42 percent to 30 percent.
} 


\section{Product Structure}

The Ring program went from proposal to launch in one year, soliciting the first cardholders through a prescreened direct mail campaign in April 2012. Barclays used prescreen direct mail to exercise more control over the size of the program at launch and the expected credit risk of the portfolio. A less targeted, broadly marketed program risks ballooning to an unmanageable size or experiencing excessive acquisition costs as the lender sifts through high volumes of unqualified responders. Maintaining a target loss rate was essential to the long-term success of the program, based on the product features that were included.

While the core Ring product is a relatively standard general-purpose credit card, a large number of potential product features were considered during the development to set the program apart in the marketplace. Barclays launched with some unique features that it believed addressed typical customer concerns with credit cards:

- Simple Annual Percentage Rate (APR): Ring offered a single APR of 8.00 percent when it launched, differentiating itself from other premium credit products at the time that often referenced multiple APRs depending on the customer's credit and averaged 14.22 percent. $^{3}$ Wilmore noted that 8.00 percent was selected to distinguish Ring by avoiding the stereotypical "marketing speak" of 7.99 percent.

Additionally, Ring did not offer a promotional APR for balance transfers, although it did offer to transfer balances with no transaction fee. ${ }^{4}$ Balance transfer promotional APRs were common marketing offers at the time. A card with a low contract APR and no balance transfer fee is ideal for customers who want to revolve balances, so Barclays designed a process that allowed customers to use other cards to make purchases, then automatically transfer those balances to the Ring card for a lower contract rate. This encouraged customers who revolve balances from month-to-month to move balances to Ring, generating growth quickly.

- No Rewards: Wilmore identified rewards as a major expense and a source of consumer dissatisfaction with card programs, generally manifested through complaints and customer

\footnotetext{
${ }^{3}$ Author's calculation from Mintel Comperemedia data. Based on Credit Card Acquisition mailings for similar card programs between January and June 2012, 37 percent of offers referenced multiple go-to APRs. The average lowest APR offered was 14.22 percent. Mailings with multiple APRs averaged a lowest rate of 12.07 percent, while mailings with a single APR (like Ring) averaged 15.5 percent APR.

${ }^{4}$ Promotional rates for balance transfers have been common features of credit card marketing for decades. Customers pay as low as a zero percent APR on transferred balances for a set time frame, after which the APR reverts to the higher contract APR. At the time of Ring's launch, the average promotional offer for balance transfer among similar products was 0.33 percent for 14 months (Mintel Comperemedia).
} 
service call center volume. ${ }^{5}$ Despite this, rewards have become table stakes in any premium credit card program, with upward of 89 percent of credit cardholders having a rewards product and 95 percent of spend taking place on rewards products (Akana 2019). Barclays developed an alternative that it believed would encourage engagement in a similar manner but aligned with the goals of the experiment.

Instead of a standard cashback or miles-based reward program, Ring incentivizes customers by sharing a portion of the program's estimated profits across the customer base. This gives the customers a more vested interest in the program's success and controls expenses by requiring minimum profit before the sharing occurs. Cardholders also have the option to donate the profit sharing to a charitable organization.

- Community Profit and Loss (P\&L): Perhaps the most radical product-level experiment Barclays launched was sharing the financial results of Ring with community members, a step that was necessary to support profit sharing. Allowing cardholders to see a $\mathrm{P} \& \mathrm{~L}$ for the program fulfilled Barclays' transparency goal and served as the baseline for adjustments to the program over time. Community members can see high-level charts of P\&L categories or drill down to detailed income and expense line items to understand how the program makes money (Figure 1). Wilmore commented that the most highly detailed versions were often cited by customers as a strong benefit, but that they were not accessed as frequently as the high-level information.

Once Barclays settled on a product construct it believed would be compelling, it had decisions to make relating to the proposed online community.

\section{Background on Online Communities - Existing Research and Concepts}

To understand the task that Barclays had set for itself (launch, grow, and maintain a robust and active online community), it helps to review some of the scholarly work relating to online communities. Much of that work appears in the literature relating to information systems, software development, and other technically oriented publications, largely because the earliest online communities coalesced around groups of users in those disciplines. Malinen (2015) provides a detailed review of the literature relating to user participation in online communities. More recently, work examining online communities in the context of consumer brands and financial services have begun to appear as company-run online

\footnotetext{
${ }^{5}$ While the specific costs of rewards programs are difficult to locate, a review of the 2017 annual reports of seven large credit card issuers in the U.S. (JPMorgan Chase, Citibank, Bank of America, Capital One, Wells Fargo, American Express, and Discover) shows that all of them cited rewards cost as a driver of revenue decreases, a risk to future forecasts, or a source of increased competition.
} 
communities have gained visibility (Shang, Chen, and Liao 2006; Wirtz, Ambtman, Bloemer et al. 2013). Many common observations relating to the success of online communities appear throughout the literature, allowing us to focus on a few key items for this discussion. In this section, we will provide an overview of these concepts before going into detail on Barclays' Ring community.

Much of the early research focused on how to define online communities in general. Social science prior to the Internet Age tended to define communities around an assumed physical proximity (your local neighborhood or workplace) or face-to-face interaction. Early online discussion forums did not clearly fit these classical definitions, since members of the group could be physically far apart and may interact only through relatively passive posting and reading messages on an electronic bulletin board. Regardless, it was clear to early researchers that participants in these forums felt a sense of community similar to that experienced in the physical world. These feelings include a sense of belonging, responsibility to the group, and an understanding of the norms and standards of the community (Blanchard and Markus, 2002; Malinen, 2015).

Communities can coalesce around a wide variety of topics and could include general interest (e.g., sailing enthusiasts, dog lovers, or science fiction fans), communities of practice (e.g., forums focused on specific careers or job functions), or brand communities (e.g., run by or focused on the users' interaction with a specific consumer brand). The user community's sense of belonging arises initially from the shared set of interests and experiences that form the basis of the group at the start. Common interests provide an automatic bridge between individuals, which provides an obvious starting point for a community (Ray, Kim, and Morris 2014).

Online brand communities (OBCs) are described by Wirtz et al. (2013) in detail and may be organized by the brand itself or by consumers of the brand separate from any corporate involvement. A number of robust brand-led communities exist, with user bases that display varying ranges of passion for the brand in question. ${ }^{6}$ The Ring community was a relatively unique form of OBC that focused on users of a newly launched single product (the Ring general-purpose credit card) within a larger brand identity (Barclays, a global financial institution with a relatively small presence in the U.S. market). Further complicating matters was the high level of distrust for financial institutions after the Great Recession; if consumers were interacting with a bank online, it was generally to complain. Barclays needed to convince customers that joining and engaging with the Ring community would be beneficial to them.

\footnotetext{
${ }^{6}$ Examples referenced by Wirtz et al. (2013) include the Harley Owners Group (Harley-Davidson Motorcycles), King Arthur Flour, and Lego. Shang et al. (2006) study an Apple Computer-related OBC.
} 
To maintain an online community over time, users must actively participate, interacting with each other and with the community leaders/brand representatives. Studies of online participation often cite a sense of responsibility to each other and to the community (a component of social capital) as one of the primary drivers of participation (Chiu, Hsu, and Wang 2006; Park, Gu, Leung, and Konana 2014; Casaló, Flavián, and Guinaliu 2011; Bateman, Gray, and Butler 2011; Preece, Nonnecke, and Andrews 2004). The vast majority of users interact passively with online information, seeking answers to questions or following discussion threads without contributing new information. If all community members do this, then the community stagnates as discussions stall and few if any new interactions take place. In a robust online community, the sense of belonging that users have developed engenders a feeling of responsibility to the community and to their fellow users. That responsibility leads users to contribute to the community by asking questions, posting comments and answers, and interacting with their peers constructively. Ultimately, they develop a desire to help the community grow and prosper by sharing their own expertise and experience with others, which becomes self-propagating in a healthy community (Koh and Kim 2004). Given that, how could a financial institution engender a sense of responsibility to its OBC in an atmosphere of distrust and unbalanced information? With Ring, we will see that the unique features of the product and how Barclays marketed the endeavor encouraged that level of responsibility and involvement early in the process.

While the development of an engaged and responsible user base is vital to an online community's long-term sustainability, success also requires a clear set of norms and standards, which are the rules of engagement, so to speak. A lack of norms can lead to a variety of negative outcomes. A lack of norms around quality and accuracy degrades users' trust in the information being shared, making participation less valuable. If the conversation is dominated by a few loud voices, other views may be excluded, ignored, or dismissed, discouraging participation in less vocal members (Haklay 2016; van Mierlo 2014). If abusive or negative language is not managed and prohibited, users will avoid interaction and leave the community. Reduced membership lowers participation rates further, leading to community stagnation and eventual dissolution.

Studies of online communities generally point to the importance of reasonable and open moderation as the key to establishing and maintaining norms (van Mierlo 2014; Harper, Frankowski, Drenner et al. 2007; Kilner and Hoadley 2005; Wang and Fesenmaier 2004). There is no standard of engagement that is appropriate for all online communities; some communities may encourage and allow more casual interactions than others. Certainly, OBCs have an incentive to establish clear norms for their users as the content of the community reflects directly on the brand itself (Shang et al. 2006; Wirtz et al. 2013). However, the norms should be clear to all users and consistently enforced as the community is 
growing. Barclays was sensitive to the risk of appearing to overly curate or police discussions, so it sought to let members speak freely while maintaining respectful tones and meaningful content. If the community has generated a user base that feels like it belongs and has internalized a sense of responsibility to the community, users will begin managing themselves within the standards.

\section{Community Engagement}

Barclays believed it had created a compelling and useful product with a unique feature set, but the purpose of the Ring experiment was to create a community, not simply to launch another variation of a credit card into an already crowded marketplace. To that end, the Ring team developed the Ring Community and looked to nonfinancial industry examples for cues to features that would prove attractive to cardholders.

The emphasis on the community began with the first Ring solicitations. The main body of the marketing piece for the April 2012 launch campaign (Figure 2) contains few references to the traditional features emphasized in credit card mail pieces. APR and fees are not mentioned until the last paragraph. Instead, the pitch to the consumer focuses on the opportunity to actively participate in the program and promises that Barclays will "show you how Barclaycard Ring makes money and how your actions can influence how much money the community gets back." Phrases such as "We want your help changing how an entire industry works," "Voice your opinions and ideas," and "Your involvement is really important" signal the potential responders that they are expected to engage with the program differently. Barclays hoped this would attract customers who would provide active feedback to the community.

Once customers are approved for a Ring card, they can register for access to the online Ring Community, accessed through Barclays' regular customer servicing site. While all Ring cardholders are eligible, they must opt in to join the community. Within the community site, they can interact with Barclays' colleagues and fellow cardholders and have access to a unique set of features. The community was designed to address the pain points that Barclays identified in the traditional relationship between issuer and customer: consumers' lack of knowledge of credit products, customer servicing and communication quality, and the perception that issuers ignore customers.

Wilmore referenced the 90-9-1 rule of online communities, popularized by Nielsen (2006) and originally articulated by Hill, Hollan, Wroblewski, and McCandless (1992): 90 percent of members will be lurkers, 9 percent will be occasional participants, and 1 percent will be superusers who generate a large majority of the content. These superusers can become ambassadors between the company and the community, as long as the company understands how to take advantage of the relationship productively. 
Nielsen cautioned that, while this ratio, with some variation, tends to hold across most online communities in which data on participation are available, ${ }^{7}$ it can lead to issues when a company tries to use the community information. When such a small percentage of users contribute the lion's share of feedback and content, the information obtained will be biased toward the views of the most vocal users. This can cause casual users to further withdraw since they believe their views won't be heard over the louder voices, skew customer feedback and reviews toward the small minority of opinion, and lead the company to make decisions based solely on fringe opinions.

Nielsen recommended several ways to address these risks. To maximize the effectiveness of the online community, companies must focus on lowering the barriers to participation, encouraging productive participation through appropriate rewards/acknowledgment, and demonstrating that participation benefits the community and the users. Barclays' Ring community design addresses many of the risks identified by Nielsen, and based on Wilmore's descriptions, the community's evolution since the launch has consistently attempted to balance openness with control.

\section{A. Getting the Customers to Engage - "Gamification" of Community Involvement}

The team at Barclays realized that a community with no member engagement would doom the experiment from the beginning. The team also understood the need to avoid having a few users take over the content and atmosphere of the site. Addressing this issue meant identifying strategies that would encourage users to actively use the message boards, take part in community events, and provide regular feedback.

To solve this problem, Barclays took cues from other successful online social networks and product-based communities, developing status levels and participation incentives to encourage members to engage. ${ }^{8}$ As community members use the card, participate in online discussions, make highly rated comments, or choose to go paperless, for instance, they earn status points and badges. Status points contribute to their public profile "Ring" (a color-coded symbol that fills in as they engage more) and their community rank (a designation of how active they are, ranging from Bronze to Paladium, which is the top $<1$ percent of community members in Figure 3 ). These public identifiers give users credibility and status

\footnotetext{
${ }^{7}$ For instance, van Mierlo (2014) examines this ratio in the context of online health communities.

${ }^{8}$ Li, Huang, and Cavusoglu (2012) and Vavilis, Petkovic, and Zannone (2014) evaluate the effectiveness of developing and using this type of reputation or gamification structure on participation.
} 
in online activities. ${ }^{9}$ Additionally, "badges" are part of the member's private profile and serve as indicators of specific completed milestones for the user (Figure 4).

To encourage the top-tier participants and to provide additional incentives for users to achieve that level, Barclays periodically creates small rewards and surprises for the most active and highest ranked community members. For instance, as a thank you to Paladium members in 2014, Barclays created custom baseball cards with members' user names, activity stats, and other information; this was an inexpensive gesture, but it received very positive feedback from the members who received them. Wilmore commented that thanking members and providing incentives for positive participation in the community does not need to be expensive.

The gamification concept directly addresses the creation of both a sense of belonging and a sense of responsibility in users. By actively acknowledging and rewarding participation, Barclays communicates that users are valued and their voices are being heard; the users feel included in the community. Those feelings of inclusion and value encourage a desire to give back to other members by participating in posting ideas, sharing experiences, and voting.

\section{B. Improving Servicing and Communication - Tapping the Community to Solve Problems}

Frustrations with issuer communications and customer service quality regularly top consumer complaints about their credit card companies. ${ }^{10}$ Prior to developing Ring, Barclays saw that customers had greater success and willingness to seek answers to credit-related questions from third-party websites and discussion forums. This raised concerns about the quality of the information being provided, and it removed any ability for issuers to manage the messaging and information about their products. Customer service is a significant expense, so any initiatives that reduce the burden on call centers are attractive. Once Barclays had the Ring customers engaged in the community, it needed to create a means of sharing

\footnotetext{
${ }^{9}$ Wilmore cited software and technical user communities such as the SAS Support Communities, developed by SAS Software, as examples of this concept. In the SAS communities, users who respond to questions and propose solutions achieve higher user levels, with recognition from the company and moderators. For instance, the home page of the SAS Support Communities page lists the top 5 "Solutions Authors" along with their community ranking.

${ }^{10}$ The Consumer Financial Protection Bureau publishes regular reports on findings gleaned from its online customer complaints portal. In the most recent report focusing on credit cards (CFPB 2017), "Customer service/Customer relations" was the seventh highest complaint reason cited based on the structured data. Analysis of the unstructured consumer narratives revealed issues relating to "confusing guidance," issuers who are "slow to respond," "confusion about how payments were applied," and "online account information [that] sometimes contradicted information received from customer service representatives."
} 
information and addressing community issues efficiently to find out whether it could provide a better servicing experience with acceptable quality and cost.

The Ask \& Answer section of the Ring Community is a message board/discussion forum in which members can post questions on topics ranging from product-specific to general credit concepts. Questions are answered by other community members or by Barclays moderators, allowing customers to get information in a more managed and curated location. Wilmore cited giffgaff Mobile, a UK mobile provider, as an example of a company that uses a consumer-centric online community rather than a call center to provide customer service; Barclays still has traditional call center agents available to assist customers but sees a decrease in call volume because of the online resources available to Ring cardholders.

Increased transparency and interaction require that community members also have good resources to help them understand their own finances and the underlying drivers of a credit card program. Barclays addressed this through educational materials on topics ranging from managing overall debt to improving credit scores ${ }^{11}$ and by holding discussion panels with internal and external experts on a variety of topics, with the subjects driven largely by community feedback. For instance, shortly after Barclays launched its free FICO score product, the Ring Community held its first “Ask FICO” online event to allow community members to learn more about the score information they were now receiving. Ring cardholders posted 130 questions over 12 days, with each question answered by FICO representatives. The postevent discussion board remains a valuable source of information for community members.

To address consumer complaints that issuer communications were often confusing and unhelpful, Barclays worked to create more explicit and user-friendly communications to be used whenever adverse action was communicated. For example, one customer contacted the Ring team through the community when his credit limit was reduced through an automated risk management strategy. He expressed confusion and frustration that one of the reasons provided for the reduction was high utilization of his credit limits; he raised the reasonable challenge that it was not made clear anywhere in the account materials that using a high percentage of the provided limit could be perceived negatively. In a traditional servicing model, this interaction would likely have taken place directly between the customer and a call center agent, and the likelihood of the customer receiving a satisfactory response would have been lower. In the Ring model, the customer could pose the question in a way that included the rest of the community

\footnotetext{
${ }^{11}$ On the publicly accessible Ring Community blog page as of February 26, 2019, visitors can see featured posts including "Tax Tips for Small Businesses," "6 Financial Planning Tips for Gen X and Y," and "3 Money Experts Explain How They Remain Calm When the Market Fluctuates.”
} 
(fulfilling the desire to be responsible to fellow users) and allowed Barclays to consider the usefulness and transparency of her response to the community as a whole.

In this case, Barclays worked to develop additional education materials for the community and explained the impacts of utilization and high balances on risk scores. Notably, this interaction did not result in a change to the account management strategies (although a review of the strategies did take place), but instead, it prompted Barclays to reexamine how the outcome of the strategies was perceived and understood by cardholders who experienced the most impact. Wilmore noted that legal limitations around the content and format of some communications limited how far this idea was pushed for individual customer communications.

Since launching Ring, Barclays has closely managed the size of the program, both to ensure that the volume of customer-level interactions within the community is manageable and to maintain rigorous control over default rates. Marketing tests have included competing strategies such as balance transfer promotions, heavier or lighter emphasis on the benefits of community membership, or higher focus on the available digital support and resources. Barclays shares testing results with the community and solicits feedback on future offers from the members, increasing the transparency of the relationship and giving members a say in the future of the endeavor, thus reinforcing the sense of ownership and responsibility.

\section{Listening to Customers - Implementing Community Ideas and Voting on Changes}

Sharing the Ring P\&L with the community constitutes a high level of financial transparency for Barclays. Sharing the program profits with the community gives members a genuine stake in the success of the program. However, the consumer relationship with the bank is generally one sided in relation to the management of the program or development of new features. Consumers often complain that issuers change the rules of their credit card on a whim, without explaining why or providing any feedback to users about the underlying mechanics of the change. Transparency and profit sharing are both unique features; however, they do not change the fact that Barclays would still have full control over how the program was run. Barclays launched two features to address this situation: ideation and voting.

Barclays actively seeks feedback from the Ring Community, not just through the discussion boards, but in the form of ideas submitted by members. Ideas can address changes to the program, new add-on products, or anything else that community members believe would improve their experience with the program and the company. Community members can browse submitted ideas and flag those they like, allowing the most popular items to gain additional traction. Barclays commits to reviewing and evaluating all of the submissions and provides regular updates to the submitter and the community about the status of 
the ideas. As of late 2018, more than 460 ideas have been submitted, with 31 implemented and 80-plus currently undergoing business review.

Wilmore cited the Ring ideation process as the source of one of Barclays' highest profile launches, the release of the Free FICO product to its full customer base in 2013, which was one of the first of its kind in the U.S. credit card market and originated with an idea submitted by a Ring member. ${ }^{12}$ Even if not feasible, ideas provide direction to the product team and may result in related changes; for example, Wilmore commented that many customers submit ideas requesting a rewards program. This prompted the Ring team to create and publish a FAQ and educational page on the Ring site explaining the economics of rewards programs and providing detailed forecasts of how Ring would be affected by that type of change.

Perhaps the most distinctive expression of the community-driven ethos in the Ring program is the opportunity for community members to vote on changes that affect the product. Ring appears to be the only lending product in the market that allows its accountholders input at this level into the program management, since the choices presented to the community often directly impact the financial results.

The first product decision made by the community in May 2012 established program rules for late fee waivers (Figure 5). Barclays presented two options: Option A) allow a three-day forgiveness period for late payments but do not allow any late fee waivers, or Option B) allow no forgiveness period for late payments but grant one late fee waiver every 12 months at the customer's request. Voters also saw the impact of each option on the program's revenue line (Option B was projected to generate 15 percent more revenue than Option A), and with that information, Option B was selected.

It would be easy to assume that the profit-sharing aspect of the program leads voters to always select the highest revenue option, but that has not always been the case in practice. Indeed, during discussions relating to the upcoming votes, Wilmore noted that members often think more about the full picture of changes, accepting trade-offs of cost, revenue, and convenience when deciding how to vote. For instance, in March 2014, community members overwhelmingly voted in favor of keeping all account servicing onshore to a maintain higher quality of service (despite cost savings if offshore servicing became the standard) and voted to reduce foreign transaction fees from 1 percent to 0 percent. The net effect of those two choices would have been a decrease in overall profit for the programs; however, in the same vote, members elected to increase the cash advance fee from $\$ 1$ to $\$ 3$, offsetting some of the lost

\footnotetext{
${ }^{12}$ Wilmore presented a workshop in November, 2014 on Barclays' launch of the free FICO product. See Mikhed (2015) for a detailed discussion of that workshop.
} 
revenue. Members were ultimately able to decide what particular costs they were willing to accept (Figure $6)$.

In addition to choices relating to the financial aspects of the program, Ring members have participated in a member-nominated charities program to donate a portion of profits, and they have selected new card art as well. Wilmore reported that product design questions generate 10 percent to 15 percent voter participation, with card art and related questions garnering 20 percent to 25 percent participation. With active prompting through email reminders, they have seen up to 40 percent of community members voting. Because many of the votes relate to substantive aspects of the program and users are able to see direct changes as a result, the voting process is a great tool to encourage and foster members' senses of responsibility to each other.

\section{Results}

The details of Ring's unique product and community features are interesting; however, if they are not yielding actionable data and meeting Barclays' expectations for performance, then the program will struggle to survive within a larger portfolio. Wilmore stated that the Ring experiment up to this point has met or exceeded his expectations regarding the knowledge gained and performance.

From a product interest and community participation perspective, Ring has grown steadily since 2012, with approximately 55,000 registered community members as of 2018 (about 25 percent of the total number of Ring cardholders). Registered members are active as well, generating 220 message board posts each month in 2018, nearly 2 million cumulative page views, and more than 70,000 Ask \& Answer page views since launch.

Barclays estimated that Ring would show a number of benefits over traditional products, including a 25 percent lower servicing cost. These savings are possible through the simpler product (no rewards, no promotional pricing, and simpler fees addressed 50 percent of complaints on traditional products) and the higher levels of engagement with high-quality digital resources. Wilmore reported that Ring has indeed seen measurable impacts, achieving 15 percent to 30 percent improvement in customer contact rates over other Barclays Branded Consumer Card products. Complaint volumes are lower as well, showing close to 20 percent improvements. With those improvements comes a concurrent impact to Relationship Net Promoter Score (RNPS), ${ }^{13}$ with Ring customers reporting 25 percent higher satisfaction

\footnotetext{
${ }^{13}$ Net Promoter Score (NPS) is a common industry service metric that measures the likelihood that a customer will recommend or promote your company to others based on their experience with you. "Relationship" NPS is based on
} 
scores versus other Barclays' products and slightly higher than comparable competitor products. Among Ring cardholders, registered community members report 10 percent higher RNPS scores than nonmembers.

Account performance results are mixed. For example, Barclays expected the higher levels of engagement by Ring cardholders to result in an increased percentage of balances that revolved monthover-month and a decreased default rate. Wilmore noted that Ring has experienced a 15 percent to 20 percent higher rate of revolving balances than comparable programs, likely driven by the low APR and easy balance transfer processes. However, the expected default rate improvements have not materialized as clearly as the benefits to the balance revolve rate. The default rate for the Ring product is low, largely because Barclays focused on cleaner credit, better established customers who revolve balances to build the portfolio. As mentioned previously, the low APR and simpler fee structure of the product dictated that the loss rate for the portfolio had to be managed closely. Payment and default rates are less susceptible to direct community influence. While members encourage each other to pay on time and have a variety of resources explaining the impact of defaults on the $\mathrm{P} \& \mathrm{~L}$, members do not know about the payment habits of other members (unless individuals choose to share) and are not in a position to influence their peers directly. In addition, communication, privacy, and collections regulations strictly dictate Barclays' available actions in the case of past due customers. This generally means that customers who miss payments will experience collections and charge-off processes that are invisible to the community.

\section{The Next Stage of Communities at Barclays}

Wilmore discussed some of the key learnings about the community itself in his closing comments.

Company commitment to the project is critical. Wilmore cited the decision to hire nonbankers to drive the design and launch of the community as a key early decision because it allowed higher levels of creativity and risk-taking in the early stages. As the program matured, background support structures for evaluating member ideas, managing "real-time" communications on message boards (and the compliance/reputation risks that type of communication entails), and developing educational materials for the community grew in importance and required ongoing support. The amount of financial and organizational overhead contributed to the decision to closely manage program growth over time. Still, the program's value to Barclays' general portfolio practices continues to grow (e.g., the development of higher profile services such as the free FICO product that originated through the Ring community).

the customer's overall experience as opposed to "Transactional" NPS, which is based on specific service interactions (https://www.netpromoter.com/know/). 
Wilmore stated that the community can provide huge value, but it should not be taken for granted. The benefits Barclays observes in the Ring product are an outcome of an actively encouraged and supported group of users providing information, interaction, and validation to each other. The 1 percent of users in the highest engagement category are the main reason for that because they serve as the guides for the majority of the community. Supporting and acknowledging their participation through gamification allows them to genuinely advocate for the company and the community. On the other hand, expecting them to shoulder too high a responsibility for success can backfire. Wilmore noted that the earliest implementations of the voting process involved monthly votes and frequent requests for input from the community. The members gave swift and direct feedback that "We do not work for you" and that Barclays should not expect to use them as test subjects in an experiment. Barclays embraced that feedback, adjusted the voting schedules to an annual basis, and began listening to customers rather than constantly probing them for answers. As Wilmore stated, customers will give you feedback if you give them a platform, but you have to commit to hearing them and responding.

The relative success of the Ring program begs the question of whether the idea of a customerdriven, transparent credit card program can be expanded beyond this tightly managed population. Wilmore addressed this question by focusing on the aspects of the Ring Community that he believes can be most effectively applied elsewhere.

The clearest benefits to the Ring model from the issuer's perspective are in servicing costs, account activation, and RNPS measures. The self-service and community discussion features could be applied across a larger customer base to reduce call volumes and reclaim control over customer questions that are now going to third-party sources on the Internet. With gamification and superuser rewards encouraging productive and active engagement, a broader cardholder community could expand the benefits across a larger portfolio.

Barclays launched some of these concepts in its Barclaycard Travel Community in 2014, an online travel community targeted at customers who carry a card from the Barclays Arrival+ travel rewards program. The Travel community implements many of the customer service and engagementrelated tools from Ring (discussion boards, gamification of community activities, rewards for engagement), but it does not include the additional financial transparency, voting, or ideation features.

A significant challenge to the expansion of many of Ring's features is scale. As mentioned previously, Barclays has consciously controlled the size of the Ring program to ensure that the background management and communications processes are not overwhelmed. Increasing the number of users in a Ring-like program drives up the costs of maintaining appropriate engagement with the 
community and the risks of communication failures, which could have reputational and regulatory consequences. 


\section{References}

Agarwal, Sumit, Souphala Chomsisengphet, Neale Mahoney, and Johannes Stroebel. 2014. "Regulating Consumer Financial Products: Evidence from Credit Cards," The Quarterly Journal of Economics 130(1), pp. 111-164. https://doi.org/10.1093/qje/qju037

Akana, Tom. 2019. "Consumer Payment Preferences and the Impact of Technology and Regulation: Insights from the Visa Payment Panel Study." Federal Reserve Bank of Philadelphia Consumer Finance Institute Discussion Paper 19-01. https://doi.org/10.21799/frbp.dp.2019.01.

Bar-Gill, Oren, and Ryan Bubb. 2012. "Credit Card Pricing: The Card Act and Beyond," Cornell Law Review 97(5), pp. 967-1018.

Bateman, Patrick J., Peter H. Gray, and Brian S. Butler. 2011. "Research Note - The Impact of Community Commitment on Participation in Online Communities," Information Systems Research 22(4), pp. 841-854, https://doi.org/10.1287/isre.1090.0265.

Benton, Kenneth J. 2010. "An Overview of the Regulation Z Rules Implementing the CARD Act," Consumer Compliance Outlook, First Quarter, 2010.

Blanchard, Anita L., and M. Lynne Markus. 2002. "Sense of Virtual Community-Maintaining the Experience of Belonging," in the Proceedings of the 35th Annual Hawaii International Conference on System Sciences (IEEE, January 10, 2002), pp. 3566-3575, https://doi.org/10.1109/HICSS.2002.994449.

Casaló, Luis V., Carlos Flavián, and Miguel Guinalíu. 2013. "New Members' Integration: Key Factor of Success in Online Travel Communities," Journal of Business Research 66, pp. 706-710.

Chiu, Chao-Min, Meng-Hsiang Hsu, and Eric TG Wang. 2006. "Understanding Knowledge Sharing in Virtual Communities: An Integration of Social Capital and Social Cognitive Theories," Decision Support Systems 42(3), pp. 1872-1888, https://doi.org/10.1016/j.dss.2006.04.001.

Consumer Financial Protection Bureau. 2013. CARD Act Report - A Review of the Impact of the CARD Act on the Consumer Credit Card Market, https://www.consumerfinance.gov/data-research/researchreports/card-act-report/ (accessed March 1, 2019).

Consumer Financial Protection Bureau. 2015. The Consumer Credit Card Market, https://www.consumerfinance.gov/data-research/research-reports/the-consumer-credit-card-market/, (accessed March 1, 2019).

Consumer Financial Protection Bureau. 2017. The Consumer Credit Card Market, https://www.consumerfinance.gov/data-research/research-reports/the-consumer-credit-card-market2017/ (accessed March 1, 2019).

Debbaut, Peter, Andra Ghent, and Marianna Kudlyak. 2016. "The CARD Act and Young Borrowers: The Effects and the Affected," Journal of Money, Credit and Banking 48(7), pp. 1495-151, https://doi.org/10.1111/jmcb.12340.

Haklay, Mordechai E. 2016. "Why Is Participation Inequality Important?" in C. Capineri, et al. eds., European Handbook of Crowdsourced Geographic Information. London: Ubiquity Press, 2016, pp. 35-44, https://doi.org/10.5334/bax.c.

Harper, F. Maxwell, Dan Frankowski, Sara Drenner, Yuqing Ren, Sara Kiesler, Loren Terveen, Robert Kraut, and John Riedl. 2007. "Talk Amongst Yourselves: Inviting Users to Participate in Online Conversations," in the Proceedings of the 12th International Conference on Intelligent User Interfaces (ACM, January 28-31, 2007), pp. 62-71, https://doi.org/10.1145/1216295.1216313.

Hill, William C., James D. Hollan, Dave Wroblewski, and Tim McCandless. 1992. "Edit Wear and Read Wear," in Chi 92, pp. 3-7. 
Jambulapati, Vikram, and Joanna Stavins. 2014. "Credit CARD Act of 2009: What Did Banks Do?" Journal of Banking \& Finance 46, pp. 21-30, https://doi.org/10.1016/j.jbankfin.2014.04.025.

Kilner, Peter G., and Christopher M. Hoadley. 2005. "Anonymity Options and Professional Participation in an Online Community of Practice." In the Proceedings of the 2005 Conference on Computer Support for Collaborative Learning: Learning 2005: The Next 10 Years! (International Society of the Learning Science, June 4, 2005), pp. 272-280, https://doi.org/10.3115/1149293.1149328.

Koh, Joon, and Y-G. Kim. 2004. "Knowledge Sharing in Virtual Communities: An E-Business Perspective," Expert Systems with Applications 26(2), pp. 155-166, https://doi.org/10.1016/S09574174(03)00116-7.

Li, Zhuolun, Ke-Wei Huang, and Huseyin Cavusoglu. 2012. "Quantifying the Impact of Badges on User Engagement in Online Q\&A Communities," International Conference on Information Systems 5, pp. 3798-3807.

Malinen, Sanna. 2015. "Understanding User Participation in Online Communities: A Systematic Literature Review of Empirical Studies," Computers in Human Behavior 46, pp. 228-238, https://doi.org/10.1016/j.chb.2015.01.004.

Mikhed, Vyacheslav. 2015 "Can Credit Cards with Access to Complimentary Credit Score Information Benefit Consumers and Lenders?" Federal Reserve Bank of Philadelphia Payment Cards Center Discussion Paper 15-03.

Nelson, Scott. 2018. "Private Information and Price Regulation in the U.S. Credit Card Market," mimeo, Massachusetts Institute of Technology.

Nielsen, Jakob. 2006. "The 90-9-1 Rule for Participation Inequality in Social Media and Online Communities." Nielsen Norman Group. https://www.nngroup.com/articles/participation-inequality/ (accessed January 14, 2019).

Park, Jae Hong, Bin Gu, Alvin Chung Man Leung, and Prabhudev Konana. 2014. "An Investigation of Information Sharing and Seeking Behaviors in Online Investment Communities," Computers in Human Behavior 31, pp. 1-12, https://doi.org/10.1016/j.chb.2013.10.002.

Preece, Jenny, Blair Nonnecke, and Dorine Andrews. 2004. "The Top Five Reasons for Lurking: Improving Community Experiences for Everyone," Computers in Human Behavior 20(2), pp. 201223, https://doi.org/10.1016/j.chb.2003.10.015.

Ray, Soumya, Sung S. Kim, and James G. Morris. 2014. "The Central Role of Engagement in Online Communities," Information Systems Research 25(3), pp. 528-546, https://doi.org/10.1287/isre.2014.0525.

Santucci, Larry. 2015. "A Tale of Two Vintages: Credit Limit Management Before and After the CARD Act and Great Recession," Federal Reserve Bank of Philadelphia Payment Cards Center Discussion Paper 15-01.

Shang, Rong-An, Yu-Chen Chen, and Hsueh-Jung Liao. 2006. "The Value of Participation in Virtual Consumer Communities on Brand Loyalty," Internet Research 16(4), pp. 398-418, https://doi.org/10.1108/10662240610690025.

Van Mierlo, Trevor. 2014. "The 1\% Rule in Four Digital Health Social Networks: An Observational Study," Journal of Medical Internet Research 16(2), https://doi.org/10.2196/jmir.2966.

Vavilis, Sokratis, Milan Petković, and Nicola Zannone. 2014. "A Reference Model for Reputation Systems," Decision Support Systems 61, pp. 147-154, https://doi.org/10.1016/j.dss.2014.02.002. 
Wang, Youcheng, and Daniel R. Fesenmaier. 2004. "Modeling Participation in an Online Travel Community," Journal of Travel Research 42(3), pp. 261-270, https://doi.org/10.1177/0047287503258824.

Wirtz, Jochen, Anouk Den Ambtman, Josée Bloemer, Csilla Horváth, Balasubramanian Ramaseshan, Joris Van De Klundert, Zeynep Gurhan Canli, and Jay Kandampully. 2013. "Managing Brands and Customer Engagement in Online Brand Communities," Journal of Service Management 24(3), pp. 223-244, https://doi.org/10.1108/09564231311326978. 
Figure 1: Ring Profit and Loss Data Available to Members (All Ring materials supplied by

\section{Barclays)}

High Level P\&L

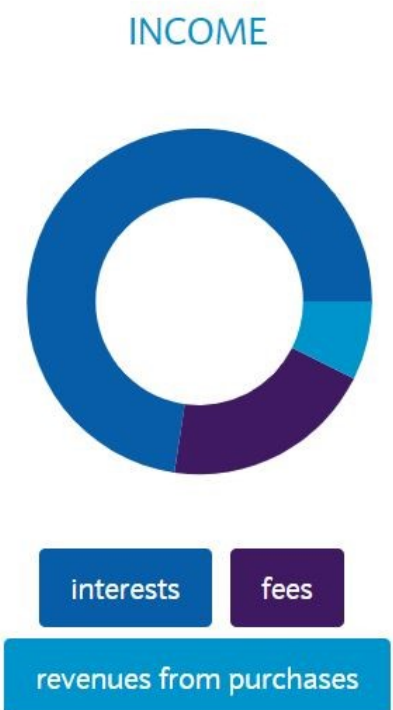

protection-services 


\section{Figure 2: Early Ring Solicitation Materials}

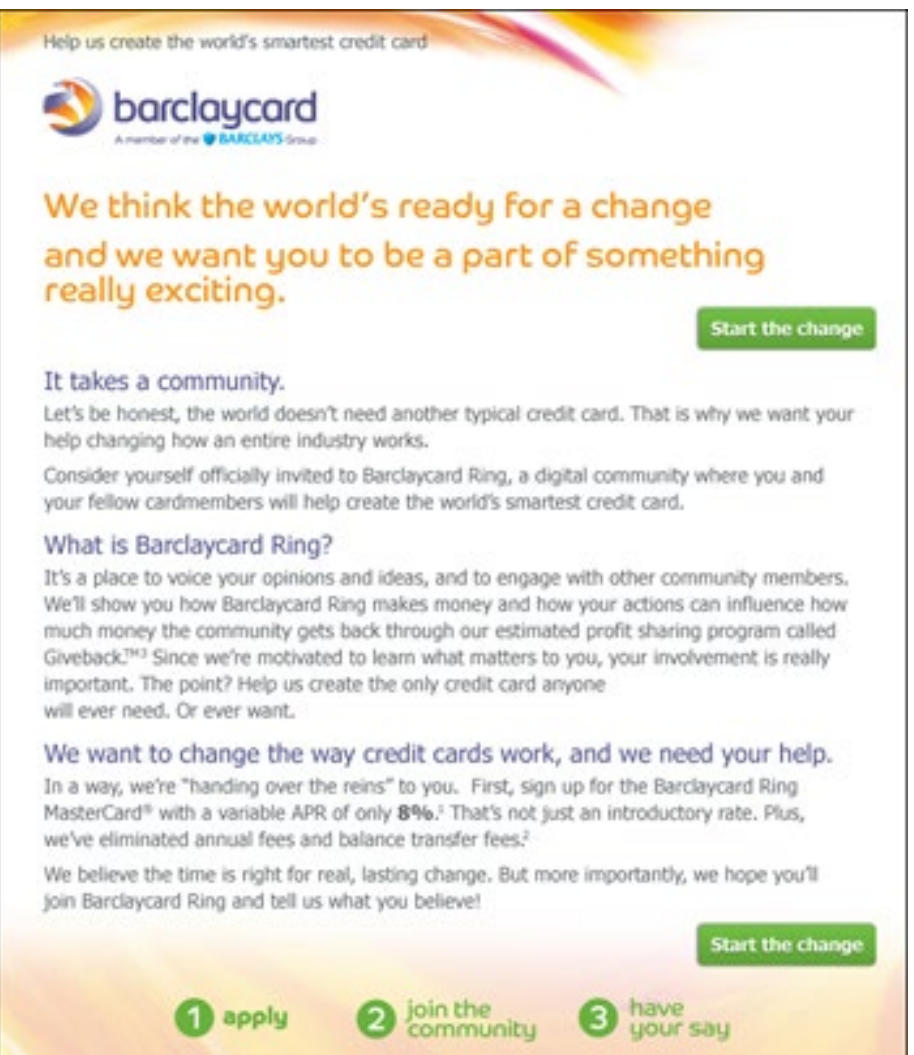

Figure 3: Customer Activity Ring and Community Rank

YOUR RING

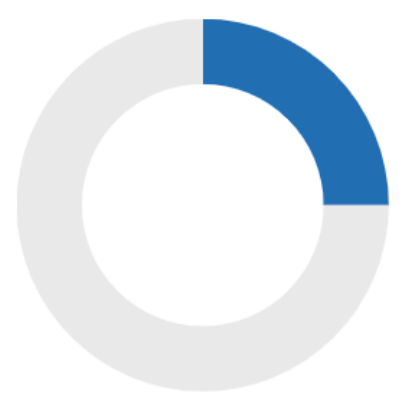

\section{credit card activity}

Using Barclaycard Ring and paying on time is definitely achievementworthy.

\section{community participation}

Chime in on a conversation or start your own

\section{paperless}

If one thousand of us go paperless, we could save $\$ 5,000$ a year, which we'll pass onto you.

\section{CA-credit}

Paladium 
Figure 4: Customer Badges

\section{BADCES}

Community Health

$\square\}$ Active

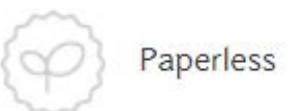

$\{8\}$ Recruiter

$\{2\}$ Campaign manager

\{S\} Repeat payer
Community Engagement

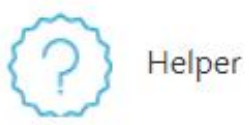

$\{\Omega\}$ Adviser

Commentator

Innovator

Most kudoed
Specialty

\{0 Trailblazer

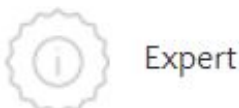


Figure 5: Materials Explaining Late-Fee Waiver Choices to Members Prior to May 2012 Vote

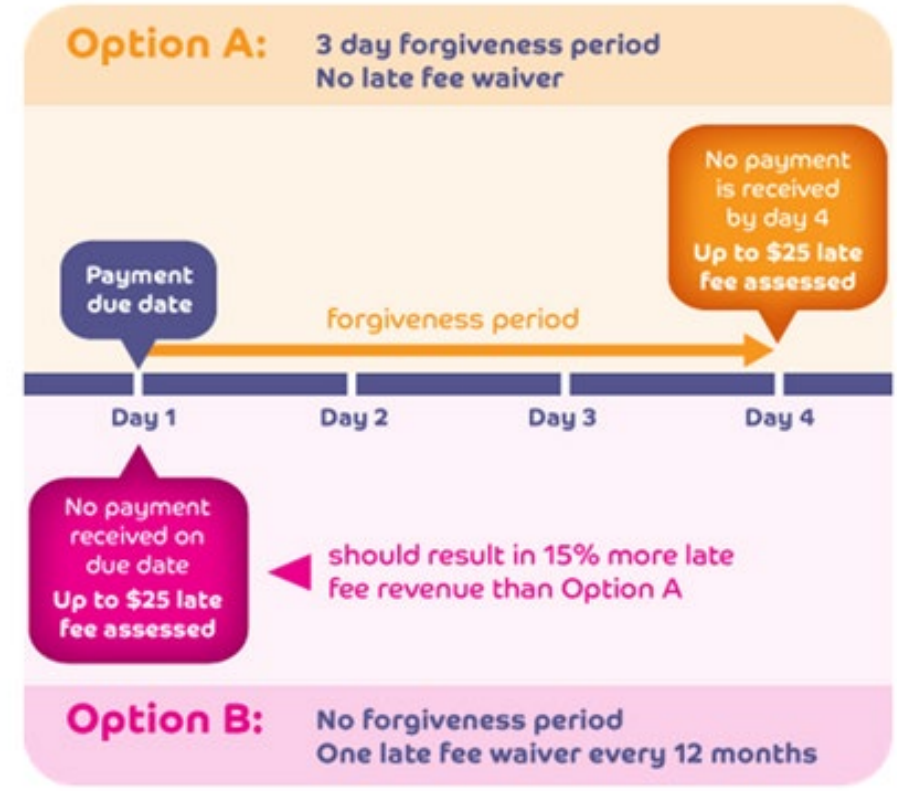

Figure 6: Results of Offshore Servicing Vote

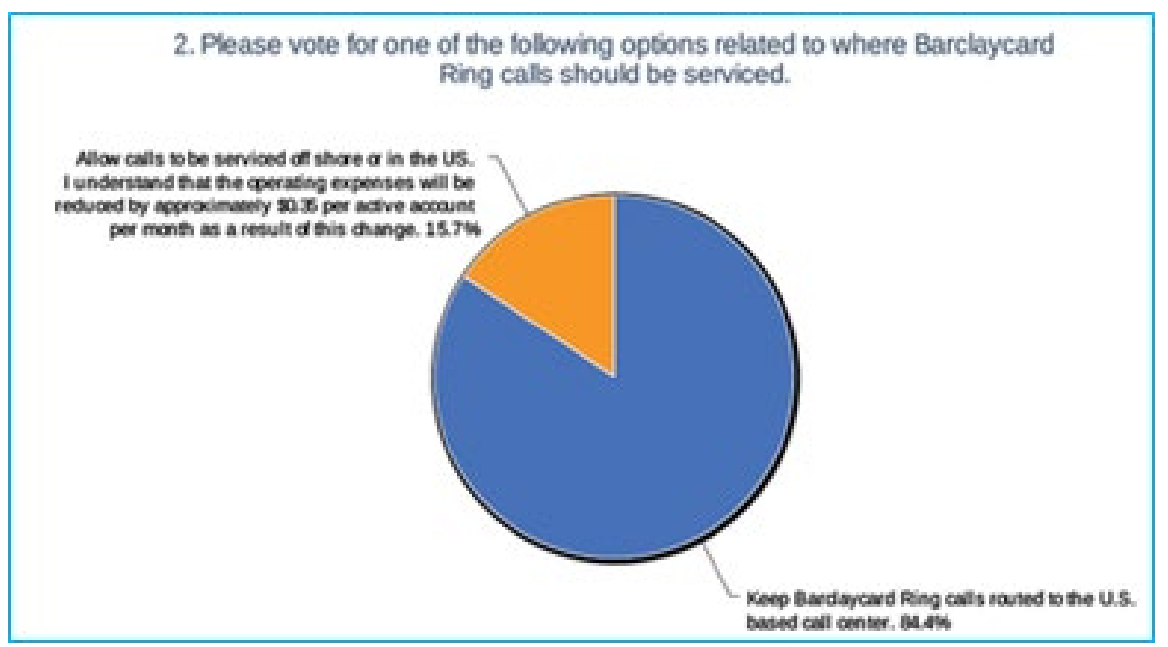




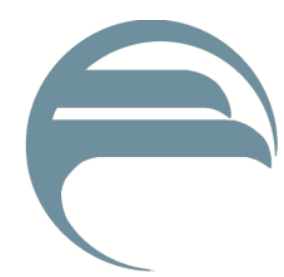

FEDERAL Reserve BANK of PHILADELPHiA

Consumer Finance Institute Discussion Paper Series

http://www.philadelphiafed.org/consumer-finance-institute 